\title{
REVIEW
}

Open Access

\section{Seeking the state of the art in standardized measurement of health care resource use and costs in juvenile idiopathic arthritis: a scoping review}

Michelle M. A. Kip ${ }^{1}$ D, Gillian Currie, ${ }^{2,3}$, Deborah A. Marshall², Luiza Grazziotin Lago², Marinka Twilt4, Sebastiaan J. Vastert ${ }^{5}$, Joost F. Swart ${ }^{5}$, Nico Wulffraat ${ }^{5}$, Rae S. M. Yeung ${ }^{6}$, Susanne M. Benseler ${ }^{4}$, Maarten J. IJzerman ${ }^{1 *}$ and on behalf of the UCAN CAN-DU Health Economics Working Group

\begin{abstract}
Background: This study aims to describe current practice in identifying and measuring health care resource use and unit costs in economic evaluations or costing studies of juvenile idiopathic arthritis (JIA).

Methods: A scoping review was conducted (in July 2018) in PubMed and Embase to identify economic evaluations, costing studies, or resource utilization studies focusing on patients with JIA. Only English language peer-reviewed articles reporting primary research were included. Data from all included full-text articles were extracted and analysed to identify the reported health care resource use items. In addition, the data sources used to obtain these resource use and unit costs were identified for all included articles.
\end{abstract}

Results: Of 1176 unique citations identified by the search, 20 full-text articles were included. These involved 4 full economic evaluations, 5 cost-outcome descriptions, 8 cost descriptions, and 3 articles reporting only resource use. The most commonly reported health care resource use items involved medication (80\%), outpatient and inpatient hospital visits (80\%), laboratory tests (70\%), medical professional visits (70\%) and other medical visits (65\%). Productivity losses of caregivers were much more often incorporated than (future) productivity losses of patients (i.e. $55 \%$ vs. 15\%). Family borne costs were not commonly captured (ranging from 15\% for school costs to 50\% for transportation costs). Resource use was mostly obtained from family self-reported questionnaires. Estimates of unit costs were mostly based on reimbursement claims, administrative data, or literature.

Conclusions: Despite some consistency in commonly included health care resource use items, variability remains in including productivity losses, missed school days and family borne costs. As these items likely substantially influence the full cost impact of JIA, the heterogeneity found between the items reported in the included studies limits the comparability of the results. Therefore, standardization of resource use items and unit costs to be collected is required. This standardization will provide guidance to future research and thereby improve the quality and comparability of economic evaluations or costing studies in JIA and potentially other childhood diseases. This would allow better understanding of the burden of JIA, and to estimate how it varies across health care systems.

Keywords: Health resources, Health care costs, Juvenile idiopathic arthritis, Review

\footnotetext{
* Correspondence: m.j.jizzerman@utwente.nl

'Department of Health Technology and Services Research, Faculty of

Behavioural, Management and Social Sciences, Technical Medical Centre,

University of Twente, P.O. Box 217, 7500, AE, Enschede, the Netherlands

Full list of author information is available at the end of the article
}

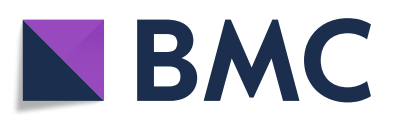

(c) The Author(s). 2019 Open Access This article is distributed under the terms of the Creative Commons Attribution 4.0 International License (http://creativecommons.org/licenses/by/4.0/), which permits unrestricted use, distribution, and

reproduction in any medium, provided you give appropriate credit to the original author(s) and the source, provide a link to the Creative Commons license, and indicate if changes were made. The Creative Commons Public Domain Dedication waiver (http://creativecommons.org/publicdomain/zero/1.0/) applies to the data made available in this article, unless otherwise stated. 


\section{Background}

Juvenile idiopathic arthritis (JIA) is the most common chronic rheumatologic disease in childhood [1]. Children with JIA suffer from joint inflammation, stiffness, contractures, and pain, which can lead to fatigue, growth abnormalities and functional impairment [2-5]. Due to its chronic nature, children diagnosed with JIA are at higher risk of developing behaviour and/or psychiatric disorders (e.g. social isolation, depression, anxiety) [6, 7], they miss more school or work days due to symptoms or medical appointments $[8,9]$, and have lower Health-Related Quality of Life (HRQoL) [6] than their peers. In addition, there is an associated risk of developing extra-articular diseases such as uveitis, which may lead to blindness if left undiagnosed or untreated [2]. Treatment of JIA consists of a combination of pharmacological, physical and occupational therapy, and psychological support [3]. In patients with active disease or with inadequate response to conventional pharmacological treatment (e.g. MTX, NSAIDs and DMARDs), the use of a (much more expensive) biologic DMARD is recommended $[4,10,11]$.

Besides the direct negative health impact of JIA, it may result in lifelong functional limitations [12], lower educational attainment [13], higher unemployment rates [13] and lower HRQoL [14, 15]. In addition, JIA does not only affect the patient, but it also leads to significant out-of-pocket costs and to productivity losses for parents or caregivers (i.e. absenteeism and presenteeism). Consequently, JIA is associated with considerable financial burden to society.

In order to analyse the cost impact of JIA, it is necessary to identify, measure and value resource use associated with the treatment or management strategies. These costs can be measured in a full economic evaluation, in which both costs and outcomes of alternative treatment or management strategies are analysed. Costs can also be measured in partial economic evaluations such as a cost description or a cost-outcome description [16]. Identifying the perspective of the analysis (ranging from health care system to full societal), determines what categories of costs are included in these analyses. As illustrated above, the impact of JIA (in terms of costs and health outcomes) cannot be fully captured by only considering the health care related costs of JIA, such as physician visits, the use of medication, or hospitalizations. Instead, it should also capture the costs of JIA borne outside of the health care sector, including productivity losses (not only for patients, but also for parents, caregivers or siblings), as well as out-of-pockets costs, such as costs for home and/or car alterations, extra school costs, transportation costs, etc. Therefore, when performing an economic evaluation of JIA, the use of a societal perspective is recommended [17, 18]. Although general guidance on conducting and reporting economic evaluations is available [19-21], these do not include a standardized list of resource use items or any standardized resource use data collection instrument to include in such evaluations. There have been efforts to standardize these resource use items but to date this is limited to adult conditions in the UK from a payer perspective [22]. In addition, two recent systematic reviews did not identify any validated standardized instruments for collecting health care resource use in children [23, 24]. Although a number of (non-validated) instruments for different childhood diseases (although not including JIA) can be found in an online database of such instruments, there is considerable variation in the resource use items they include [25]. We therefore concluded there is no standardized guidance regarding what types of resource use items to include in an economic evaluation of interventions for childhood diseases generally, nor for JIA specifically.

This study therefore aims to describe current practice on identification and measurement of health care resource use in the health economic literature on JIA. It is hypothesized that the lack of available guidance will be reflected in literature. A second objective is to identify commonly used sources to collect health care resource use and unit costs. ${ }^{1}$ The findings from this study will be taken into account in a multicenter, international collaborative project into management strategies for JIA, conducted in the Netherlands and Canada, named UCAN CAN-DU. ${ }^{2}$ The results of the current study will, ultimately, facilitate the identification of a standard set of core resource use items to improve the quality and comparability of health economic evaluations of JIA interventions.

\section{Methods}

A scoping review was conducted to identify resource use items and unit costs included in economic evaluations or costing/resource utilization studies in JIA [26, 27]. The search was performed in PubMed and Embase in July 2018. JIA specific disease terms were combined with the search filters for economic evaluations as recommended by the Canadian Agency for Drugs and Technologies in Health (CADTH) [28] (Additional file 1). Studies were included if they met the following criteria: peer reviewed articles presenting primary research; the study type included a full or partial economic evaluation which included costs, or was an analysis of resource utilization; the study population focused on JIA patients and/or the potential consequences of JIA into adulthood; English language. As the aim of this scoping review was to capture current practice including all economic evaluation or costing/resource utilization studies that have been performed in JIA, a broadly defined search strategy was used (e.g. also including the abbreviations 'JA', 'JRA' and 'JCA'). Unlike with a systematic review, a quality 
assessment was not part of the inclusion criteria for this study. Duplicates were removed electronically, and then titles and abstracts were screened by two reviewers (MMAK and GC). Related published literature reviews were excluded, but the reference lists were manually searched for relevant studies [11, 29-32]. Full text review was conducted (by MMAK and GC), and disagreements resolved by consensus. A third reviewer (LGL) was available if consensus could not be reached.

All included full-text articles were analysed (by MMAK) to identify which resource use items were measured, or which items were mentioned as (potentially) relevant (e.g. in the discussion section of the manuscript) but not measured. Subsequently, for each study, the data sources used to obtain resource use and unit costs were identified.

\section{Results}

\section{Literature search}

The search strategy retrieved 950 citations in Embase and 400 in PubMed. As expected, the broadly defined search strategy resulted in the exclusion of many irrelevant articles. Figure 1 presents an overview of the selection process, using the PRISMA reporting guidelines. This process resulted in the final inclusion of 20 full-text articles, representing 19 unique studies [9, 32-50]. As two articles reported the results of the same study it was decided to include both articles in the scoping review $[47,48]$. This prevents missing any resource use or cost items, which may have occurred when not all items were mentioned in both articles. An overview of the characteristics of all included studies is provided in Table 1.

Of the 20 articles included, 7 articles explicitly reported the use of a societal perspective $[9,34,38,41$, 42,49 ] or a social perspective [44]. In addition, 17 articles used a time horizon of 1 year or less [9, 33-39, $41-44,46-50]$, and only 4 articles conducted a full economic evaluation [32, 38, 40, 49], indicating that these studies compared costs and consequences of two or more alternatives [16].

A summary of all resource use and cost items reported in the included articles is shown in Table 2. A more detailed overview is given in Additional file 2, in which we also made note of items that were mentioned as (potentially) relevant but not actually included. As the aim of the current paper was to identify which resource use and cost items related to JIA were reported in literature and how they were quantified, this study does not report the magnitude of these items or the findings of the included studies.

\section{Reporting of resource use and cost items}

As shown in Table 2, when considering medical costs, medication use was reported in 16 out of 20 articles. The remaining articles had a narrow focus (i.e. only included productivity losses, or only focused on alternative and complementary medicine), which explains why medication use was not reported. Of the 20 articles, outpatient and inpatient hospital visits were reported in 16 articles (e.g. including joint injections, day-care

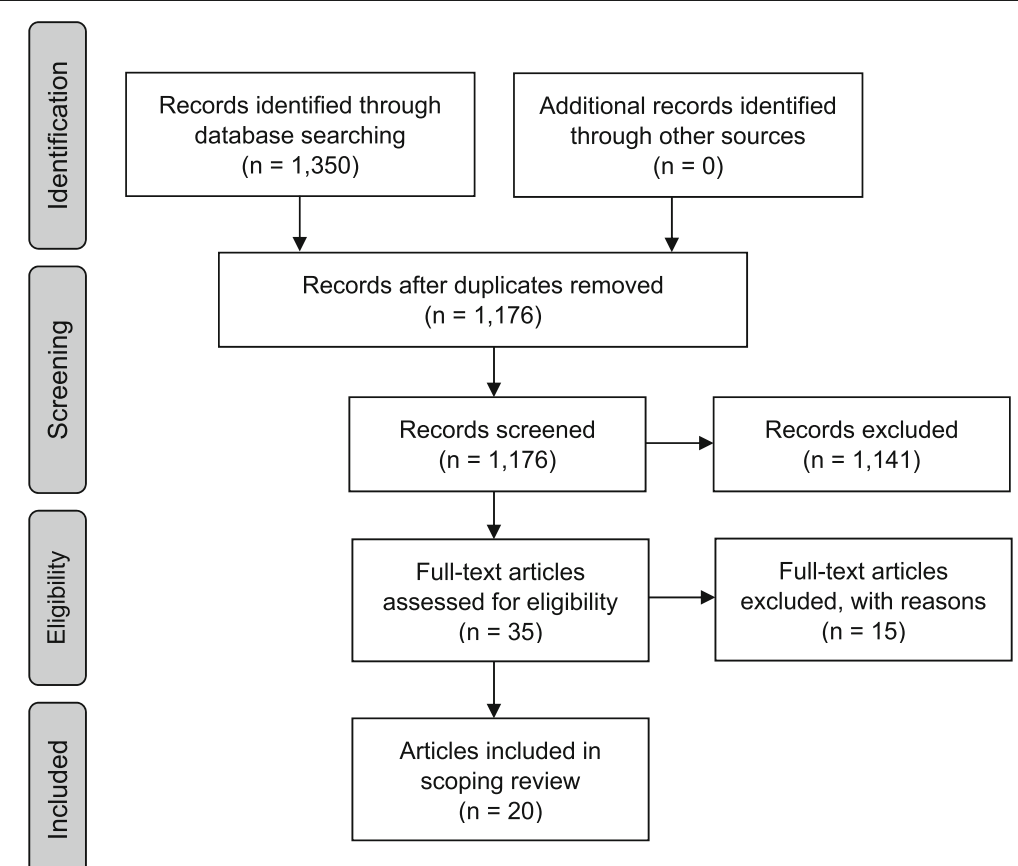

Fig. 1 PRISMA diagram. This figure shows the results of the literature search 
Table 1 Characteristics of included studies

\begin{tabular}{|c|c|c|c|c|}
\hline Country & Study & Analysis type $[16]^{a}$ & Resource use included ${ }^{b}$ & Time horizon \\
\hline \multirow[t]{5}{*}{ Canada } & Bernatsky et al. (2007) [36] & Cost description & $\begin{array}{l}\text { Health care } \\
\text { Productivity } \\
\text { School days lost }\end{array}$ & 1 year \\
\hline & Ens et al. (2013) [37] & Cost description & $\begin{array}{l}\text { Family out-of-pocket } \\
\text { Productivity }\end{array}$ & 1 year \\
\hline & Luca et al. (2016) [40] & Full economic evaluation & Health care & 5 years \\
\hline & Toupin et al. (2009) [35] & Resource use & $\begin{array}{l}\text { Family out-of-pocket } \\
\text { (complementary and } \\
\text { alternative health } \\
\text { care only) }\end{array}$ & 1 year \\
\hline & Ungar et al. (2011) [49] & Full economic evaluation & $\begin{array}{l}\text { Health care } \\
\text { Productivity }\end{array}$ & 1 year \\
\hline \multirow[t]{2}{*}{ Finland } & Haapasaari et al. (2004) [39] & Cost description & $\begin{array}{l}\text { Health care } \\
\text { Family out-of-pocket } \\
\text { Productivity }\end{array}$ & 1 year \\
\hline & Pohjankoski et al. (2011) [43] & Cost-outcome description & Health care & 1 year \\
\hline \multirow[t]{2}{*}{ Germany } & Minden et al. (2004) [41] & Cost description & $\begin{array}{l}\text { Health care } \\
\text { Family out-of-pocket } \\
\text { Productivity }\end{array}$ & 1 year \\
\hline & Minden et al. (2009) [42] & Cost description & $\begin{array}{l}\text { Health care } \\
\text { Education } \\
\text { Family out-of-pocket } \\
\text { Productivity } \\
\text { School days lost }\end{array}$ & 1 year \\
\hline The Netherlands & Prince et al. (2011) [44] & Cost-outcome description & Health care & 1 year \\
\hline \multirow[t]{4}{*}{ United Kingdom } & Angelis et al. (2016) [34] & Cost-outcome description & $\begin{array}{l}\text { Health care } \\
\text { Family out-of-pocket } \\
\text { Productivity }\end{array}$ & 1 year \\
\hline & Epps et al. (2005) [38] & Full economic evaluation & $\begin{array}{l}\text { Health care } \\
\text { Productivity }\end{array}$ & 6 months \\
\hline & Shepherd et al. (2016) [32] & Full economic evaluation & Health care & 30 years \\
\hline & $\begin{array}{l}\text { Thornton et al. (2008.1 and } \\
\text { 2008.2) [47, 48] }\end{array}$ & Cost description & Health care & 1 year \\
\hline \multirow[t]{3}{*}{ United States } & Allaire et al. (1992) [33] & Cost description & $\begin{array}{l}\text { Health care } \\
\text { Education costs } \\
\text { Family out-of-pocket } \\
\text { Productivity }\end{array}$ & 1 year \\
\hline & Rasu et al. (2015) [45] & Resource use & Productivity & 9 years \\
\hline & Seburg et al. (2015) [46] & Resource use & $\begin{array}{l}\text { Family out-of-pocket } \\
\text { (complementary and } \\
\text { alternative health } \\
\text { care only) }\end{array}$ & $\begin{array}{l}1 \text { year (inferred, but } \\
\text { not reported clearly) }\end{array}$ \\
\hline $\begin{array}{l}\text { Multiple countries } \\
\text { (Bulgaria, France, } \\
\text { Germany, Italy, Spain, } \\
\text { Sweden, United } \\
\text { Kingdom) }\end{array}$ & Kuhlmann et al. (2016) [9] & Cost-outcome description & $\begin{array}{l}\text { Health care } \\
\text { Social services } \\
\text { Family out-of-pocket } \\
\text { Productivity }\end{array}$ & 1 year \\
\hline $\begin{array}{l}\text { Multiple countries } \\
\text { (France, Germany, the } \\
\text { Netherlands, United } \\
\text { Kingdom, United } \\
\text { States) }\end{array}$ & Shenoi et al. (2018) [50] & Cost-outcome description & $\begin{array}{l}\text { Health care } \\
\text { Education } \\
\text { Family out-of-pocket } \\
\text { Productivity } \\
\text { School days lost }\end{array}$ & $\begin{array}{l}\text { Assistive devices: over } \\
\text { past } 4 \text { weeks as well from } \\
\text { time since JIA onset. } \\
\text { Productivity: } 2 \text { months }\end{array}$ \\
\hline
\end{tabular}

This table shows an overview of the studies included in the scoping review, including the country in which it was performed, the analysis type, the resource use included and the time horizon applied

${ }^{a}$ Studies quantifying only resource use were classified as such. All studies that describe both resource use and costs were classified according to Drummond et al, $2005[16]$

${ }^{\mathrm{b}}$ The studies were categorized as including health care costs, other government agency costs (education and social services), family out-of-pocket costs, productivity costs and school time lost. These are broad categories only, and does not indicate exhaustive inclusion within the category 
Table 2 Overview of cost and resource items reported in the 20 included articles

\begin{tabular}{|c|c|c|c|}
\hline \multirow[t]{2}{*}{ Category } & \multirow[t]{2}{*}{ Type of cost or resource use item } & \multicolumn{2}{|c|}{ Number of articles } \\
\hline & & $\bar{N}$ & References \\
\hline \multirow[t]{41}{*}{ Medical costs } & Medication & 16 & {$[9,32-34,36-44,47-49]$} \\
\hline & DMARDs - non biologic & 11 & {$[32,38-44,47-49]$} \\
\hline & Methotrexate (tablets or subcutaneous) & 8 & {$[32,39,40,43,44,47-49]$} \\
\hline & Cyclosporin & 3 & {$[43,47,48]$} \\
\hline & Hydroxychloroquine & 3 & {$[43,47,48]$} \\
\hline & Sulphasalazine & 3 & {$[43,47,48]$} \\
\hline & Leflunomide & 3 & {$[43,47,48]$} \\
\hline & Other, or not specified & 6 & {$[38,41-43,47,48]$} \\
\hline & DMARDs - biologic & 10 & {$[32,38-40,42-44,47-49]$} \\
\hline & Etanercept & 6 & {$[39,40,44,47-49]$} \\
\hline & Abatacept & 3 & {$[32,40,49]$} \\
\hline & Infliximab & 3 & [47-49] \\
\hline & Anti-Tumor Necrosis Factor (TNF) (not further specified) & 2 & {$[38,43]$} \\
\hline & Other, or not specified & 3 & {$[32,42,49]$} \\
\hline & Corticosteroids & 6 & {$[38,42-44,47,48]$} \\
\hline & Prednisolone & 3 & {$[43,47,48]$} \\
\hline & Glucocorticoids (systemic) & 3 & {$[42,44][43]^{*}$} \\
\hline & Other, or not specified & 3 & {$[38,47,48]$} \\
\hline & NSAIDs and analgesics & 8 & {$[38,41-44,47,48][39]^{*}$} \\
\hline & Joint injections & 8 & {$[32,37-39,44,47,48][43]^{*}$} \\
\hline & Eye drops/ointments & 3 & {$[42,47,48]$} \\
\hline & Premedication & 2 & {$[40,49]$} \\
\hline & Osteoporosis treatment/ prophylaxis & 2 & {$[41,42]$} \\
\hline & Gastroprotective agents & 2 & {$[41,42]$} \\
\hline & Other medication, or not specified & 7 & {$[9,33,34,36,38,47,48]$} \\
\hline & Outpatient and inpatient hospital visits & 16 & {$[9,32-34,36-42,44,47-50]$} \\
\hline & $\begin{array}{l}\text { Outpatient stays/day-care/visits (including joint injection, } \\
\text { and outpatient surgery) }\end{array}$ & 16 & {$[9,32-34,36-42,44,47-50]$} \\
\hline & $\begin{array}{l}\text { Inpatient stays/inpatient treatment/surgery (including } \\
\text { joint replacement) }\end{array}$ & 13 & {$[9,32,33,37-42,44,47,48,50]$} \\
\hline & Acute (including emergency room visits) & 6 & {$[34,36,37,40-42]$} \\
\hline & Rehabilitation & 5 & {$[9,34,36,41,42]$} \\
\hline & Medical professional visits & 14 & {$[9,32,34,36-38,40-42,44,47-50]$} \\
\hline & Rheumatology paediatric visit (or telephone consultation) & 9 & {$[32,37,38,41,42,44,47,48,50]$} \\
\hline & Ophthalmologist & 6 & {$[32,38,42,47,48,50]$} \\
\hline & General practitioner visits & 5 & {$[32,34,36,38,50]$} \\
\hline & Specialist nurse / district nurse & 4 & {$[32,38,47,48]$} \\
\hline & Nephrologist/endocrinologist & 3 & {$[38,47,48]$} \\
\hline & Other, or not specified & 5 & {$[9,38,40,49,50]$} \\
\hline & Other medical visits (including paramedical care) & 13 & {$[32,33,35,37-39,41,42,44,46-48,50]$} \\
\hline & $\begin{array}{l}\text { Physiotherapist (at health centre or at home), including } \\
\text { hydrotherapy }\end{array}$ & 11 & {$[32,33,37-39,41,42,44,47,48,50]$} \\
\hline & Occupational therapist & 7 & {$[32,38,41,42,47,48,50]$} \\
\hline & Podiatrist/orthotics & 4 & {$[32,38,47,48]$} \\
\hline
\end{tabular}


Table 2 Overview of cost and resource items reported in the 20 included articles (Continued)

\begin{tabular}{|c|c|c|c|}
\hline \multirow[t]{2}{*}{ Category } & \multirow[t]{2}{*}{ Type of cost or resource use item } & \multicolumn{2}{|c|}{ Number of articles } \\
\hline & & $\mathrm{N}$ & References \\
\hline & Psychologist/counsellor & 4 & {$[38,47,48,50]$} \\
\hline & Chiropractic & 2 & {$[35,46]$} \\
\hline & Other, or not specified & 4 & {$[35,38,42,46]$} \\
\hline & Laboratory tests & 14 & {$[9,32-34,36,38-42,44,47-49]$} \\
\hline & Haemoglobin & 4 & {$[32,38,47,48]$} \\
\hline & Haematocrit & 4 & {$[32,38,47,48]$} \\
\hline & Platelets & 4 & {$[32,38,47,48]$} \\
\hline & White blood cell count & 4 & {$[32,38,47,48]$} \\
\hline & C-reactive protein (CRP) & 3 & {$[32,47,48]$} \\
\hline & Liver function test & 2 & {$[32,38]$} \\
\hline & Tuberculosis screening & 1 & [49] \\
\hline & Other, or not specified & 12 & {$[9,32-34,36,39-42,44,47,48]$} \\
\hline & Imaging & 11 & {$[9,32-34,36,38,40,44,47-49]$} \\
\hline & Radiography (X-ray) & 7 & {$[32,33,38,44,47-49]$} \\
\hline & Magnetic resonance imaging (MRI) & 5 & {$[32,38,44,47,48]$} \\
\hline & Ultrasound & 5 & {$[32,38,44,47,48]$} \\
\hline & Dual-energy X-ray absorptiometry (DEXA) scan & 4 & {$[32,44,47,48]$} \\
\hline & Other, or not specified & 5 & {$[9,34,36,38,40]$} \\
\hline & Splints and/or devices & 11 & {$[9,33,34,36,37,40-42,47,48,50]$} \\
\hline & $\begin{array}{l}\text { Orthopaedic devices (casts/splints/braces/ambulation } \\
\text { aids wheelchair/stroller/walker frame) }\end{array}$ & 8 & {$[9,33,36,37,42,47,48,50]$} \\
\hline & Other, or not specified & 5 & {$[34,37,40-42]$} \\
\hline & $\begin{array}{l}\text { Supplements and/or alternative medicine (e.g. vitamins, } \\
\text { minerals, herbal medicine) }\end{array}$ & 8 & {$[35,38,41,42,46-49]$} \\
\hline & Folic acid & 3 & [47-49] \\
\hline & Other, or not specified & 7 & {$[35,38,41,42,46-48]$} \\
\hline & Drug administration costs & 6 & {$[32,37,39,47-49]$} \\
\hline & $\begin{array}{l}\text { Administering joint injections (incl. appointment and/or } \\
\text { anaesthesia) }\end{array}$ & 4 & {$[37,39,47,48]$} \\
\hline & Intravenous infusion (including bags and solutions) & 3 & {$[32,37,49]$} \\
\hline & $\begin{array}{l}\text { Other injections, which may include monitoring (by } \\
\text { nurse/caregiver), and which may include training } \\
\text { and/or caregiver time }\end{array}$ & 3 & {$[32,39,49]$} \\
\hline & Other, or not specified & 1 & [49] \\
\hline & Overhead/fixed resources & 1 & [38] \\
\hline \multirow[t]{8}{*}{ Out-of-pocket patient/family costs } & Transportation costs & 10 & {$[9,33,34,36,37,39,41,42,44,50]$} \\
\hline & Transportation, non-medical (including toll) & 7 & {$[9,33,34,37,39,41,42]$} \\
\hline & Transportation, medical & 5 & {$[9,34,37,39,42]$} \\
\hline & Other, or not specified & 3 & {$[36,44,50]$} \\
\hline & (Other) out-of-pocket costs & 9 & {$[33,35,37,39-42,44,50]^{*}$} \\
\hline & $\begin{array}{l}\text { Home adaptations and special equipment (toilet seat } \\
\text { appliance, bathtub or shower appliance, stair lift) }\end{array}$ & 5 & {$[33,37,41,42,50]$} \\
\hline & $\begin{array}{l}\text { Childcare for babysitting, also for other children (during } \\
\text { medical visits/hospitalization of diseased child) }\end{array}$ & 4 & {$[33,37,42,50]$} \\
\hline & Caregivers' accommodations (e.g. when child is & 4 & {$[33,37,50][39]^{*}$} \\
\hline
\end{tabular}


Table 2 Overview of cost and resource items reported in the 20 included articles (Continued)

\begin{tabular}{|c|c|c|c|}
\hline \multirow[t]{2}{*}{ Category } & \multirow[t]{2}{*}{ Type of cost or resource use item } & \multicolumn{2}{|c|}{ Number of articles } \\
\hline & & $\mathrm{N}$ & References \\
\hline & Extra telephone costs & 3 & {$[33,37,42]$} \\
\hline & Parking (for hospital and other medical visits) & 3 & {$[33,37,50]$} \\
\hline & Money spend on food during medical visits & 2 & {$[33,37]$} \\
\hline & Other, or not specified & 3 & {$[35][40,44]^{*}$} \\
\hline & $\begin{array}{l}\text { Social care services/home care/private and community } \\
\text { services/ domestic help }\end{array}$ & 4 & {$[9,34,41,42]$} \\
\hline & $\begin{array}{l}\text { Use of social care services (i.e. formal (paid) care) and } \\
\text { professional caregivers, including home medical care }\end{array}$ & 2 & {$[9,34]$} \\
\hline & Use of private and community services/domestic help & 2 & {$[41,42]$} \\
\hline & School costs & 3 & {$[33,42,50]$} \\
\hline \multirow[t]{10}{*}{ Productivity costs } & Productivity loss of caregivers (including informal caregiving) & 14 & {$[9,33,34,36-42,44,45,49,50]^{*}$} \\
\hline & $\begin{array}{l}\text { Work/sick leave due to child's illness, time lost due to } \\
\text { health care appointments and/or due to informal } \\
\text { caregiving (absenteeism) }\end{array}$ & 12 & {$[9,33,34,36-39,42,45,49,50][41]^{*}$} \\
\hline & Cease employment/early retirement & 3 & {$[9,34,50]$} \\
\hline & $\begin{array}{l}\text { Other, or not specified (including reduced number of } \\
\text { working hours, and presenteeism) }\end{array}$ & 3 & {$[50][40,44]^{*}$} \\
\hline & Missed school days and productivity loss of patients & 8 & {$[9,33,34,36,40-42,50]^{*}$} \\
\hline & Sick leave from school & 4 & {$[36,42,50][41]^{*}$} \\
\hline & Sick leave from work & 3 & {$[9,34,41]$} \\
\hline & Cease employment/early retirement & 3 & {$[9,34,41]$} \\
\hline & Impact on future employment ability & 3 & {$[33,36,40]^{*}$} \\
\hline & Missed school days of siblings & 1 & {$[50]$} \\
\hline
\end{tabular}

This table shows the costs or resource use items that are either measured in the articles from the scoping review or mentioned as relevant items. A further specification of these items was shown in the second column, and the number of articles and accompanying references in which these items were measured are shown in columns three and four. In case items were only mentioned (e.g. in the study's discussion section), this is indicated with an asterisk (*). Items that were only included in one study or not specified in detail, were summarized into the category 'Other, or not specified'

admissions and hospitalizations), medical professional visits in 14 articles (e.g. paediatric rheumatologists or other physician visits), and 13 articles reported other medical visits (including paramedical care). Laboratory tests were reported in 14 articles, and imaging in 11 articles. Other health care related items that were reported involved splints and/or devices (11 articles), the use of supplements/alternative medicine (8 articles), drug administration (6 articles) and hospital overhead (i.e. heating, lighting and administration) (1 article).

Of the 8 articles that reported the use of supplements or alternative medicine, 2 articles specifically investigated the use of complementary and/or alternative medicine, and did not estimate the accompanying impact on costs $[35,46]$. In these studies, the percentage of patients using complementary and alternative health care was found to range between $36 \%$ (within a one-year period) [35] and 72\% (without specifying a time horizon) [46].

With regard to out-of-pocket payments and (other) family costs, transportation costs were found to be reported in 10 articles, (other) out-of-pocket costs in 9 articles, social care services and/or home care in 4 articles, and (additional) school costs in 3 articles.

Productivity losses by parents and/or caregivers were mentioned in 14 articles, although only 11 actually included it in their evaluation. The remaining 3 articles did mention parents' productivity losses but did not aim to include it in their evaluation $[40,41]$, or could not include it because parents were reluctant to fill out cost diaries [44]. In contrast, when considering the child with JIA, missed school days or productivity losses were mentioned in 8 articles, but only included in 6 articles. In addition, 1 article (also) reported the impact on siblings [50].

Although 4 articles included or mentioned adverse events, side effects and/or complications due to the disease and/or treatment $[32,36,40,50]$, these were not included as a separate category as these involve hospital visits, treatment, and other items already included in Table 2. Similarly, costs of JIA over the long term were included or mentioned in 8 articles [32, 34, 36, 37, 40, 47-49], but (whenever possible) the accompanying resource use items (e.g. surgery and treatment) were captured in the other items. 
Data sources used to obtain resource use and unit costs The main data sources or data collection instruments where resource use was obtained from are: questionnaires or inquiry with parent(s), caregivers or child; chart review, medical records, or patient files; published or accessible data(bases) or literature; physician inquiry or expert opinion; and (case) report forms or other data collection methods (Table 3).

When considering the data sources used to obtain unit costs, the results indicate that these are most commonly based on: medical charges or reimbursement fees; published or available data(bases), literature, or guidelines; hospital-based fees or costs; and questionnaire or inquiry with the parent(s) or the child (Table 4). The impact of JIA on missed school days could not be expressed in monetary units.

\section{Discussion}

Medication use, outpatient and inpatient hospital visits, medical professional, other medical visits, and laboratory tests were found to be the most commonly reported health care related resource use items. Besides these, when considering resource use items related to costs of lost productivity and costs borne by families, productivity losses among parents and/or caregivers were most frequently reported. However, the extent and way these are incorporated differs considerably between studies. Other resource use items to quantify impacts outside the health care system, including social care services, school costs, school days lost and productivity losses among patients, as well as transportation costs and (other) out-of-pocket costs, were less frequently reported.

The most commonly reported resource use items (i.e. medication, medical professional and other medical visits, outpatient and inpatient hospital visits) mirror the core items identified for an adult generic health care resource use instrument [51], with the addition of laboratory testing. The addition of laboratory testing in the JIA population aligns with clinical practice, given that the medications prescribed require regular lab monitoring (both in adults and children). In addition, the relatively common inclusion of productivity losses of caregivers is reflective of this unique consideration in the evaluation of childhood diseases.

When considering the 20 articles included, there is strong variation in the perspectives (or combination of perspectives) that were applied. In addition, the great majority of these studies used a one-year time horizon, although this is insufficient to capture the full economic implications of childhood diseases like JIA. The choice for these different perspectives and time horizons may however be partly explained by the different aims of the articles, ranging from (specifically) investigating out-ofpocket costs and the use of complementary or alternative health care $[35,37,46]$, to investigating a specific intervention or type of medication [38, 44, 49]. Therefore, the high heterogeneity between the articles in this scoping review limits their comparability. In addition, as studies are performed in different countries, with different health care systems, the resource use and cost items covered may differ between these health care systems, thereby further limiting the comparability between the studies in this scoping review. Consequently, the full health economic impact of JIA cannot be reliably quantified.

Although questionnaires or inquiry with parent(s) or the child were found to be the most frequently used data source to obtain resource use, the impact of JIA on societal costs (including lost productivity) is often not incorporated. More specifically, the impact of JIA in terms of missed school days was only incorporated in 3 articles (although none of them quantified this impact in terms of costs), making it likely that many health economic evaluations underestimated the full potential impact of JIA.

Although medical records will likely represent the most reliable source of evidence for collecting medical resource use (in contrast to questionnaires or inquiry with parents), results indicate that this is not common practice. As results from questionnaires are prone to recall bias, the accuracy of the outcomes of these studies may be limited. When considering unit costs, the results indicate that these were most frequently obtained from medical charges or reimbursement fees, or from published or available data(bases), literature, or costing guidelines. Although medical charges and reimbursement fees may not provide the actual costs incurred by the health service provided, they are however often considered the best available source of evidence.

This is the first study to provide a comprehensive overview of all resource use items included in studies evaluating JIA-related resource use and/or costs. Although some resource use items identified (e.g. splints and devices) may be specific to JIA, most items will also apply to other (chronic) childhood diseases. However, as mentioned previously, no validated health care resource data collection instrument for children could be found. Therefore, the results from the current study, in terms of the importance of improved guidance regarding how to quantify resource use and unit costs, are likely also valuable to other (chronic) childhood diseases.

The results of this scoping review are limited by the quality of reporting on the included resource use items. One limitation concerns the level of detail reported for each item. For example, although medical professional visits were included in most of the articles, the type of medical professional that was consulted was not always stated explicitly. This lack of detail limits the transparency and reproducibility of the study's results. 


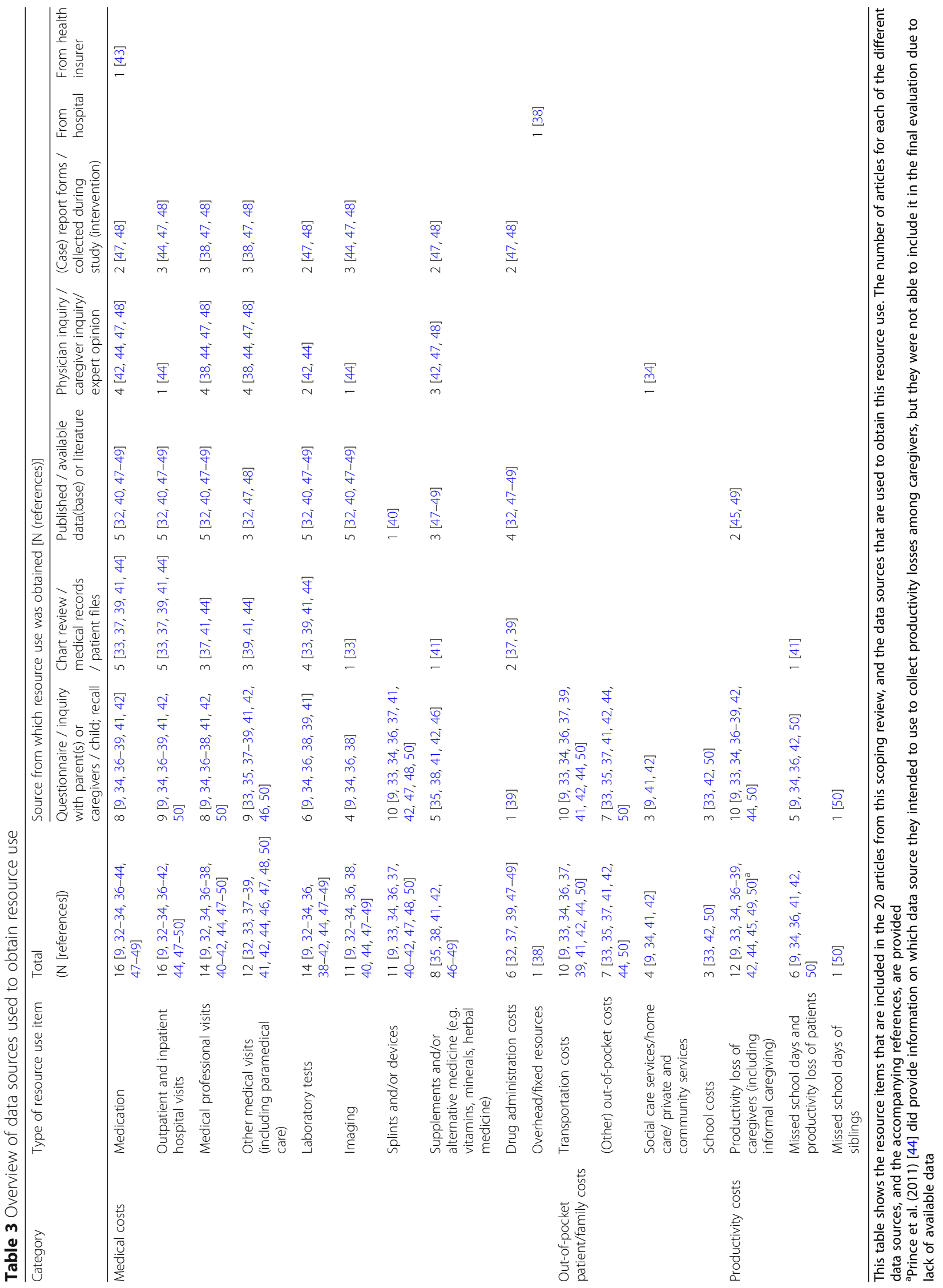




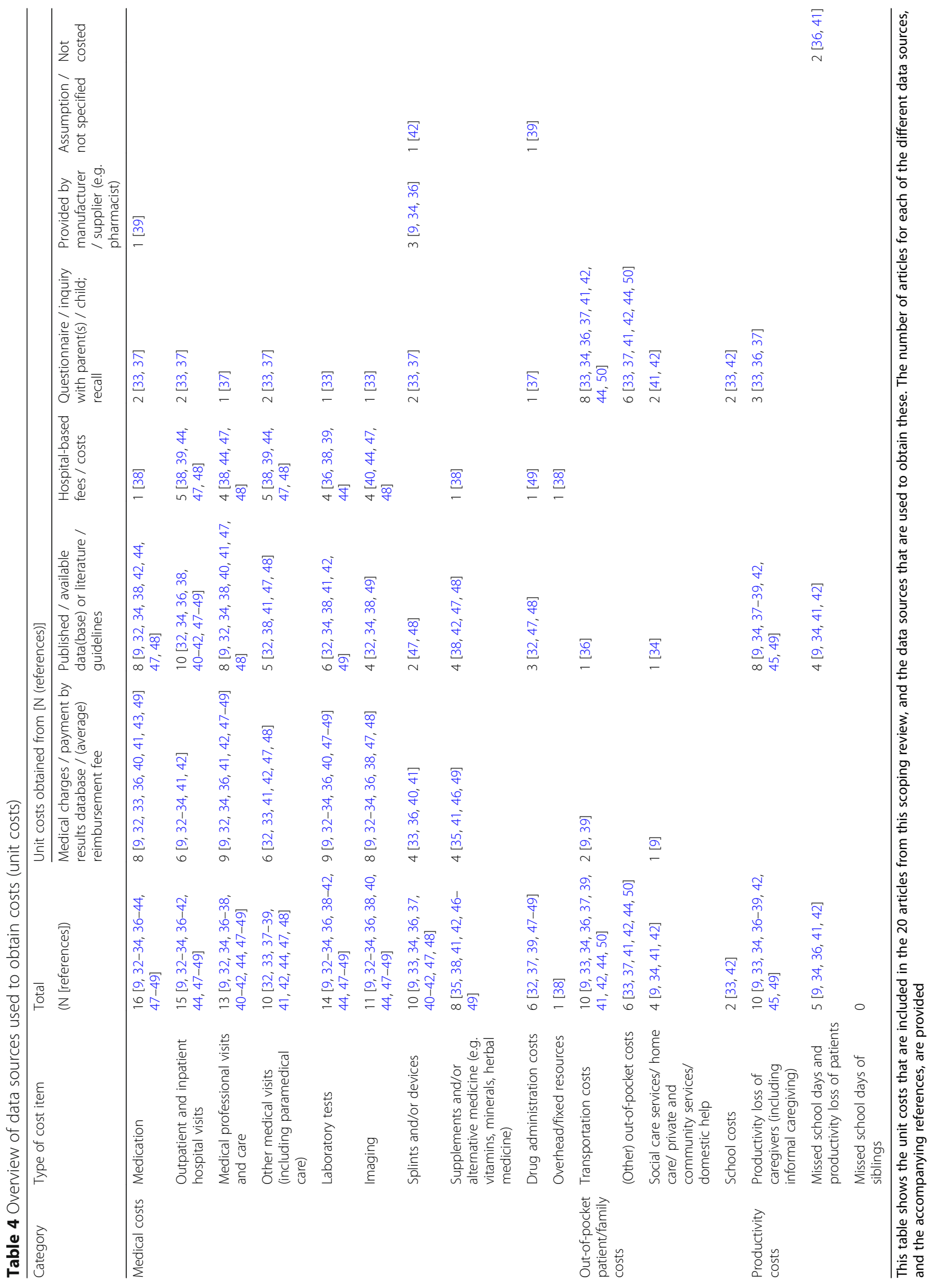


Another limitation concerns the accuracy in reporting data sources for quantifying resource use and obtaining unit costs. This specification is often general, for example stating that all resource use was obtained from physician inquiry and/or available literature, or stating that all medical costs were obtained from medical charges and/or published literature, without exactly specifying which data source was used.

In health economic evaluations, the use of a wider and/ or societal perspective is increasingly recommended as the preferred perspective, and is required when it is likely that this wider and/or societal impact will substantially impact the results $[17,18,52]$. Thus, as JIA leads to productivity losses among both patients and parents and/or caregivers $[9,34,36]$ and comes with significant costs borne by families, it can be concluded that this impact is often overlooked as only 7 out of 20 articles report the use of a societal (or social) perspective. More specifically, when considering the resource use and costs that were actually included in these 7 articles, this varies from only incorporating health care costs and productivity losses (although use of the term societal perspective should not be justifiable purely based on the inclusion of productivity losses [53]), to also incorporating out-of-pocket costs, lost school days, social costs, and/or costs of education. Thus, there is great variation in the way the societal perspective is conceptualized and interpreted in economic evaluations, which has also been reported in literature [53, 54].

Another aspect that may be overlooked in economic evaluations of JIA concerns the use of complementary and alternative health care. As the results of the current study show that this type of health care is used by a substantial proportion of JIA patients, incorporating the accompanying costs is likely relevant to capture out-of-pocket costs for families. Consequently, current economic evaluations of JIA (as well as other (chronic) childhood diseases) may underestimate the real-life impact of JIA.

In addition, the terminology used to state the perspective of the evaluation was not always clear. To illustrate this, 2 articles that reported either the use of a 'direct medical cost perspective' [36] or a 'direct and indirect cost perspective' [39] both reported (besides medical costs) working time lost from parents or caregivers and/or family borne costs. Consequently, the quality and comparability of studies evaluating resource use and costs in JIA would benefit from improved guidance regarding: 1) which perspective can and should be applied, 2) which cost and resource use items should be included, and 3) how these items can be quantified. Such improved guidance will likely increase the quality and comparability between these studies [51], both for JIA as well as for other chronic childhood diseases.

\section{Conclusions}

Although there is some consistency in terms of items that are included in studies examining resource use and unit costs of JIA from the health care system perspective, there is heterogeneity in what is included within perspectives going beyond that. However, as the impact of productivity losses and family borne costs among JIA patients (and among other chronic childhood diseases) pose a substantial burden to society, these studies should go beyond the health care system perspective to capture this full societal impact. Therefore, improved guidance for conducting and reporting (health) economic evaluations of JIA is required. This can be achieved by the development of a standardized list of items for collecting resource use and unit costs in chronic childhood diseases. In particular it should be emphasized how to quantify this societal impact of these childhood diseases over a prolonged time-period. Incorporating these recommendations will likely increase the quality and comparability of health economic evaluations of both JIA and other chronic childhood diseases.

\section{Endnotes}

${ }^{1}$ The term 'unit costs' indicates the mean costs per unit. The total costs per resource use item can be calculated by multiplying the unit costs with the accompanying resource utilization.

${ }^{2}$ UCAN CAN-DU is the Canada-Netherlands Personalized Medicine Network in Childhood Arthritis and Rheumatic diseases.

\section{Additional files}

Additional file 1: Overview of search strategy. This file provides an overview of the search strategy performed in Embase and in PubMed. (DOCX $17 \mathrm{~kb}$ )

Additional file 2: Results of scoping review. This file provides an extensive overview of the results of the scoping review. (DOCX $564 \mathrm{~kb}$ )

\section{Abbreviations \\ CADTH: Canadian Agency for Drugs and Technologies in Health; DIRUM: Database of Instruments for Resource Use Measurement; DMARD: Disease-modifying antirheumatic drug; HRQOL: Health-related quality of life; JIA: Juvenile idiopathic arthritis; MTX: Methotrexate; NSAIDs: Non-steroidal anti-inflammatory drugs; UCAN CAN-DU: Canada- Netherlands Personalized Medicine Network in Childhood Arthritis and Rheumatic diseases}

\section{Acknowledgements}

We would like to thank all members from the UCAN CAN-DU Health Economics Working Group: Gouke Bonsel, Brian M. Feldman, Esther Hoppenreijs, Bianca Lang, Claire LeBlanc, Ana Sepulveda, Karine ToupinApril, Philomine van Pelt, Annet van Royen-Kerkhof.

\section{Funding}

This work was supported by the Canadian Institutes for Health Research (Canada) [grant number 381280]; Genome Canada (Canada); ZonMW (the Netherlands); and the Reumafonds (the Netherlands). 


\section{Availability of data and materials}

All data generated or analysed during this study are included in this published article and its supplementary information files.

\section{Authors' contributions}

MMAK, GC, DAM, LGL, MT and MJIJ were involved in the conception and design of the study. MMAK and GC conducted the scoping review and analysed the included articles. All authors were involved in interpreting the results. MMAK and GC drafted the manuscript, and all other authors were major contributors in critically reviewing the manuscript. All authors read and approved the final manuscript.

\section{Ethics approval and consent to participate}

Not applicable.

\section{Consent for publication}

Not applicable.

\section{Competing interests}

The authors declare that they have no competing interests.

\section{Publisher's Note}

Springer Nature remains neutral with regard to jurisdictional claims in published maps and institutional affiliations.

\section{Author details}

${ }^{1}$ Department of Health Technology and Services Research, Faculty of Behavioural, Management and Social Sciences, Technical Medical Centre, University of Twente, P.O. Box 217, 7500, AE, Enschede, the Netherlands. ${ }^{2}$ Department of Community Health Sciences, Cumming School of Medicine, University of Calgary, Calgary, Alberta, Canada. ${ }^{3}$ Department of Paediatrics, Cumming School of Medicine, University of Calgary, Calgary, Alberta, Canada. ${ }^{4}$ Division of Rheumatology, Department of Pediatrics, Alberta Children's Hospital, Cumming School of Medicine, University of Calgary, Calgary, Alberta, Canada. ${ }^{5}$ Division of Paediatrics, Department of Paediatric Rheumatology, University Medical Center Utrecht, Wilhelmina Children's Hospital, Utrecht, The Netherlands. ${ }^{6}$ Division of Rheumatology, Department of Paediatrics, The Hospital for Sick Children, University of Toronto, Toronto, Ontario, Canada.

\section{Received: 22 January 2019 Accepted: 11 April 2019}

\section{Published online: 06 May 2019}

\section{References}

1. Manners PJ, Bower C. Worldwide prevalence of juvenile arthritis why does it vary so much? J Rheumatol. 2002;29(7):1520-30.

2. Moorthy LN, Peterson MG, Hassett AL, Lehman TJ. Burden of childhoodonset arthritis. Pediatr Rheumatol Online J. 2010;8:20.

3. Ravelli A, Martini A. Juvenile idiopathic arthritis. Lancet. 2007;369(9563): 767-78.

4. Ringold S, Ward TM, Wallace CA. Disease activity and fatigue in juvenile idiopathic arthritis. Arthritis Care Res. 2013;65(3):391-7.

5. Armbrust W, Lelieveld OH, Tuinstra J, Wulffraat NM, Bos GJ, Cappon J, et al Fatigue in patients with juvenile idiopathic arthritis: relationship to perceived health, physical health, self-efficacy, and participation. Pediatr Rheumatol Online J. 2016;14(1):65.

6. Muller-Godeffroy E, Lehmann H, Kuster RM, Thyen U. Quality of life and psychosocial adaptation in children and adolescents with juvenile idiopathic arthritis and reactive arthritis. Z Rheumatol. 2005;64(3):177-87.

7. Mullick MS, Nahar JS, Haq SA. Psychiatric morbidity, stressors, impact, and burden in juvenile idiopathic arthritis. J Health Popul Nutr. 2005;23(2):142-9.

8. Bouaddi I, Rostom S, El Badri D, Hassani A, Chkirate B, Amine B, et al. Impact of juvenile idiopathic arthritis on schooling. BMC Pediatr. 2013;13:2.

9. Kuhlmann A, Schmidt T, Treskova M, Lopez-Bastida J, Linertova R, OlivaMoreno J, et al. Social/economic costs and health-related quality of life in patients with juvenile idiopathic arthritis in Europe. Eur J Health Econ. 2016; 17(Suppl 1):79-87.

10. Beukelman T, Patkar NM, Saag KG, Tolleson-Rinehart S, Cron RQ, DeWitt EM, et al. 2011 American College of Rheumatology recommendations for the treatment of juvenile idiopathic arthritis: initiation and safety monitoring of therapeutic agents for the treatment of arthritis and systemic features. Arthritis Care Res. 2011;63(4):465-82.

11. Prince FH, van Suijlekom-Smit LW. Cost of biologics in the treatment of juvenile idiopathic arthritis: a factor not to be overlooked. Paediatr Drugs. 2013;15(4):271-80

12. Flato B, Aasland A, Vinje O, Forre O. Outcome and predictive factors in juvenile rheumatoid arthritis and juvenile spondyloarthropathy. J Rheumatol. 1998;25(2):366-75.

13. Schlichtiger J, Haas JP, Barth S, Bisdorff B, Hager L, Michels H, et al. Education and employment in patients with juvenile idiopathic arthritis - a standardized comparison to the German general population. Pediatr Rheumatol Online J. 2017;15(1):45.

14. Barth S, Haas JP, Schlichtiger J, Molz J, Bisdorff B, Michels H, et al. Long-term health-related quality of life in German patients with juvenile idiopathic arthritis in comparison to German general population. PLoS One. 2016;11(4): e0153267.

15. Tollisen A, Selvaag AM, Aulie HA, Lilleby V, Aasland A, Lerdal A, et al. Physical functioning, pain and health-related quality of life in adults with juvenile idiopathic arthritis: a longitudinal 30-year follow-up study. Arthritis Care Res. 2018;70(5):741-749

16. Drummond MF, Sculpher MJ, Claxton K, Stoddard GL, Torrance GW. Methods for the economic evaluation of health care programmes. Oxford: Oxford University Press; 2005. p. 404.

17. CADTH. Guidelines for the economic evaluation of health technologies: Canada. 3rd ed. Ottawa: Canadian Agency for Drugs and Technologies in Health; 2006.

18. NICE. Developing NICE guidelines: the manual; 2014. [Available from: https:// www.nice.org.uk/process/pmg20/chapter/introduction-and-overview]

19. CADTH. Guidelines for the economic evaluation of health technologies: Canada. 4th ed. Ottawa: CADTH; 2017.

20. Husereau D, Drummond M, Petrou S, Carswell C, Moher D, Greenberg D, et al. Consolidated health economic evaluation reporting standards (CHEERS) statement. Value Health. 2013;16(2):e1-5.

21. Zorginstituut Nederland. Richtlijn voor het uitvoeren van economische evaluaties in de gezondheidszorg. 2016.

22. Thorn JC, Brookes ST, Ridyard C, Riley R, Hughes DA, Wordsworth S, et al. Core items for a standardized resource use measure: expert Delphi consensus survey. Value Health. 2018;21(6):640-9.

23. Leggett LE, Khadaroo RG, Holroyd-Leduc J, Lorenzetti DL, Hanson H, Wagg $A$, et al. Measuring resource utilization: a systematic review of validated selfreported questionnaires. Medicine (Baltimore). 2016;95(10):e2759.

24. Noben CY, de Rijk A, Nijhuis F, Kottner J, Evers S. The exchangeability of self-reports and administrative health care resource use measurements: assessement of the methodological reporting quality. J Clin Epidemiol. 2016:74:93-106 e2.

25. DIRUM. Database of Instruments for Resource Use Measurement [Available from: http://www.dirum.org/].

26. Arksey H, O'malley L. Scoping studies: towards a methodological framework. Int J Soc Res Methodol. 2005;8(1):19-32.

27. Mays N, Roberts E, Popay J. Synthesising research evidence. In: N. Fulop, P. Allen, A. Clarke, N. Black, editors. Methods for studying the delivery and organisation of health services. London: Routledge; 2001.

28. CADTH. Strings attached: CADTH database search filters [internet]. Ottawa: CADTH; 2016. [cited 2017 November 17]. https://www.cadth.ca/resources/ finding-evidence/strings-attached-cadths-database-search-filters.

29. Angelis A, Tordrup D, Kanavos P. Socio-economic burden of rare diseases: a systematic review of cost of illness evidence. Health Policy. 2015;119(7):964-79.

30. Gidman W, Meacock R, Symmons D. The humanistic and economic burden of juvenile idiopathic arthritis in the era of biologic medication. Curr Rheumatol Rep. 2015;17(5):31.

31. Minden K. What are the costs of childhood-onset rheumatic disease? Best Pract Res Clin Rheumatol. 2006;20(2):223-40.

32. Shepherd J, Cooper K, Harris P, Picot J, Rose M. The clinical effectiveness and cost-effectiveness of abatacept, adalimumab, etanercept and tocilizumab for treating juvenile idiopathic arthritis: a systematic review and economic evaluation. Health Technol Assess. 2016;20(34):1-222.

33. Allaire SH, DeNardo BS, Szer IS, Meenan RF, Schaller JG. The economic impacts of juvenile rheumatoid arthritis. J Rheumatol. 1992;19(6):952-5.

34. Angelis A, Kanavos P, Lopez-Bastida J, Linertova R, Serrano-Aguilar P, B-RR N. Socioeconomic costs and health-related quality of life in juvenile idiopathic 
arthritis: a cost-of-illness study in the United Kingdom. BMC Musculoskelet Disord. 2016;17:321.

35. Toupin-April K, Feldman DE, Zunzunegui MV, Descarreaux M, Malleson $P$, Duffy CM. Longitudinal analysis of complementary and alternative health care use in children with juvenile idiopathic arthritis. Complement Ther Med. 2009;17(4):208-15.

36. Bernatsky S, Duffy C, Malleson P, Feldman DE, St Pierre Y, Clarke AE. Economic impact of juvenile idiopathic arthritis. Arthritis Rheum. 2007; 57(1):44-8.

37. Ens A, Lang B, Ramsey S, Stringer E, Huber AM. The financial burden of juvenile idiopathic arthritis: a Nova Scotia experience. Pediatr Rheumatol Online J. 2013;11(1):24.

38. Epps H, Ginnelly L, Utley M, Southwood T, Gallivan S, Sculpher M, et al. Is hydrotherapy cost-effective? A randomised controlled trial of combined hydrotherapy programmes compared with physiotherapy land techniques in children with juvenile idiopathic arthritis. Health Technol Assess. 2005; 9(39):iii-v ix-x, 1-59.

39. Haapasaari J, Kautiainen HJ, Isomaki HA, Hakala M. Etanercept does not essentially increase the total costs of the treatment of refractory juvenile idiopathic arthritis. J Rheumatol. 2004;31(11):2286-9.

40. Luca NJ, Burnett HF, Ungar WJ, Moretti ME, Beukelman T, Feldman BM, et al. Cost-effectiveness analysis of first-line treatment with biologic agents in Polyarticular juvenile idiopathic arthritis. Arthritis Care Res. 2016;68(12):1803-11.

41. Minden K, Niewerth M, Listing J, Biedermann T, Schontube M, Zink A. Burden and cost of illness in patients with juvenile idiopathic arthritis. Ann Rheum Dis. 2004;63(7):836-42.

42. Minden K, Niewerth M, Listing J, Mobius D, Thon A, Ganser G, et al. The economic burden of juvenile idiopathic arthritis-results from the German paediatric rheumatologic database. Clin Exp Rheumatol. 2009;27(5):863-9.

43. Pohjankoski H, Latva K, Kautiainen H, Saila H, Klaukka T, Virta L, et al. Firstyear purchases of disease-modifying drugs of incident patients with chronic juvenile arthritis in Finland. Clin Exp Rheumatol. 2011;29(5):878-81.

44. Prince FH, de Bekker-Grob EW, Twilt M, van Rossum MA, Hoppenreijs EP, ten Cate $R$, et al. An analysis of the costs and treatment success of etanercept in juvenile idiopathic arthritis: results from the Dutch arthritis and biologicals in children register. Rheumatology (Oxford). 2011;50(6):1131-6.

45. Rasu RS, Cline SK, Shaw JW, Hayes O, Bawa WA, Cifaldi MA. Impact of JIA on parents' work absences. Rheumatology. 2015;54(7):1177-85.

46. Seburg EM, Horvath KJ, Garwick AW, McMorris BJ, Vehe RK, Scal P. Complementary and alternative medicine use among youth with juvenile arthritis: are youth using CAM, but not talking about it? J Adolesc Health. 2012;51(2):200-2.

47. Thornton J, Ashcroft D, O'Neill T, Elliott R, Adams J, Roberts C, et al. A systematic review of the effectiveness of strategies for reducing fracture risk in children with juvenile idiopathic arthritis with additional data on longterm risk of fracture and cost of disease management. Health Technol Assess. 2008;12(3):iii-x xi-xiv, 1-208.

48. Thornton J, Lunt M, Ashcroft DM, Baildam E, Foster H, Davidson J, et al. Costing juvenile idiopathic arthritis: examining patient-based costs during the first year after diagnosis. Rheumatology (Oxford). 2008:47(7):985-90.

49. Ungar WJ, Costa V, Hancock-Howard R, Feldman BM, Laxer RM. Costeffectiveness of biologics in polyarticular-course juvenile idiopathic arthritis patients unresponsive to disease-modifying antirheumatic drugs. Arthritis Care Res. 2011:63(1):111-9.

50. Shenoi S, Horneff G, Cidon M, Ramanan AV, Kimura Y, Quartier P, et al. The burden of systemic juvenile idiopathic arthritis for patients and caregivers: an international survey and retrospective chart review. Clin Exp Rheumatol. 2018;36(5):920-928

51. Thorn JC, Brookes ST, Ridyard CH, Riley R, Hughes DA, Wordsworth S, et al. Core items for a standardized resource use measure (ISRUM): expert delphi consensus survey. Value in Health 2018;21(6):640-649.

52. Drummond $\mathrm{M}$, Weatherly $\mathrm{H}$, Ferguson $\mathrm{B}$. Economic evaluation of health interventions. BMJ. 2008:337:a1204.

53. Drost $R$, van der Putten IM, Ruwaard D, Evers S, Paulus ATG Conceptualizations of the societal perspective within economic evaluations: a systematic review. Int J Technol Assess Health Care. 2017;33(2):251-60.

54. Garrison LP Jr, Mansley EC, Abbott TA 3rd, Bresnahan BW, Hay JW Smeeding J. Good research practices for measuring drug costs in costeffectiveness analyses: a societal perspective: the ISPOR drug cost task force report--part II. Value Health. 2010;13(1):8-13.

\section{Ready to submit your research? Choose BMC and benefit from}

- fast, convenient online submission

- thorough peer review by experienced researchers in your field

- rapid publication on acceptance

- support for research data, including large and complex data types

- gold Open Access which fosters wider collaboration and increased citations

- maximum visibility for your research: over $100 \mathrm{M}$ website views per year

At $\mathrm{BMC}$, research is always in progress.

Learn more biomedcentral.com/submissions 